\title{
Effect of Deformation Temperature on Mechanical Properties in 1-GPa-grade TRIP Steels with Different Retained Austenite Morphologies
}

\author{
Noriyuki TSUCHIDA, ${ }^{1 *}$ Takaaki TANAKA ${ }^{2)}$ and Yuki TOJI ${ }^{2)}$ \\ 1) Graduate School of Engineering, University of Hyogo, 2167 Shosha, Himeji, 671-2280 Japan. \\ 2) Steel Research Laboratory, JFE Steel Co., 1 Kawasaki-cho, Chuo-ku, Chiba, 260-0835 Japan.
}

(Received on June 24, 2020; accepted on September 7, 2020)

\begin{abstract}
The effect of deformation temperature on the mechanical properties of 1-GPa-grade TRIP steels with different retained austenite $\left(\gamma_{R}\right)$ morphologies was studied. The temperature dependence on the deformation-induced martensitic transformation behavior was also investigated. The uniform elongation below room temperature was relatively large in the needle-like $\gamma_{R}$ steel, whereas the tensile strength at each temperature was almost the same as it was independent of the $\gamma_{R}$ morphology. The better tensile strength-uniform elongation balance was obtained at $373 \mathrm{~K}$ for the needle-like $\gamma_{R}$ steel and at $473 \mathrm{~K}$ for blocky $\gamma_{R}$ one. The mechanical stability of $\gamma_{R}$ was higher in the needle-like $\gamma_{R}$ steel, according to the $x$-ray diffraction experiments. $\gamma_{R}$ was mechanically stable with increasing temperature, but its volume fraction decreased at temperatures above $473 \mathrm{~K}$ because of the deformation-induced bainitic transformation. In this paper, the quantitative conditions of deformation-induced transformation to obtain better uniform elongation in the 1-GPa-grade TRIP steels are summarized from the viewpoints of the volume fraction of deformation-induced martensite and the transformation rate.
\end{abstract}

KEY WORDS: TRIP; TRIP-aided multi-microstructure steel; temperature; deformation-induced martensitic transformation.

\section{Introduction}

Transformation-induced plasticity (TRIP) effect due to the deformation-induced martensitic transformation (DIMT) of retained austenite $\left(\gamma_{R}\right)$ can improve the ductility of steels and has been utilized in advanced high-strength steels (AHSS). ${ }^{1-6)}$ The tensile strength-uniform elongation balance of the third-generation AHSS is approximately 30000 $40000 \mathrm{MPa} \%,{ }^{1)}$ and various studies on AHSS with a tensile strength of more than $1 \mathrm{GPa}$ have been reported. ${ }^{1,2)} \mathrm{We}$ have been investigating the tensile deformation behavior of 1-GPa-grade TRIP steels with different $\gamma_{R}$ morphologies. ${ }^{7,8)}$ In our previous studies, the 1-GPa-grade TRIP steels with a needle-like $\gamma_{R}$ morphology (needle-like $\gamma_{R}$ steel) showed better mechanical properties at a wide range of strain rates, including high-speed deformation behavior. ${ }^{7)}$ It was found from the in situ neutron diffraction experiments ${ }^{8)}$ that not only the DIMT behavior but also the stress partitioning between the austenite $(\gamma)$ and the ferrite $(\alpha)$ phase plays an important role in the TRIP effect. The matrix microstructure of annealed martensite in the needle-like $\gamma_{R}$ steel was also found to be an important factor for the mechanical stability of $\gamma_{R}{ }^{8)}$ In order to understand the TRIP effect of the 1-GPagrade TRIP steel in more detail, it is important to drastically change the DIMT behavior, which is an essential factor influencing the TRIP effect. ${ }^{3,5-7)}$ One of the conditions to make a significant difference in the DIMT behavior is the deformation temperature. ${ }^{6,9-14)}$ Various data considerably changing the deformation temperature will lead to a deep understanding of the TRIP effect of high-strength TRIP steels. $^{5,6)}$

Therefore, in this study, the effect of the deformation temperature on the mechanical properties of the 1-GPa-grade TRIP steels with different $\gamma_{R}$ morphologies was studied. The effect of deformation temperature on the DIMT behavior in the 1-GPa-grade TRIP steels was also investigated in order to discuss the differences in their mechanical properties. Furthermore, the conditions to obtain better mechanical properties in high-strength TRIP steels were discussed by comparing with the mechanical properties of other TRIP steels.

\footnotetext{
* Corresponding author: E-mail: tsuchida@eng.u-hyogo.ac.jp
} 


\section{Experimental Procedures}

In this study, two types of 1-GPa-grade TRIP steels with different $\gamma_{R}$ morphologies obtained by using a $0.3 \mathrm{C}-1.5 \mathrm{Si}-$ $2 \mathrm{Mn}$ steel were used. One is the needle-like $\gamma_{R}$ steel, and the other is the blocky $\gamma_{R}$ one. ${ }^{7,8)}$ The details of the 1-GPa-grade TRIP steels have been reported elsewhere. ${ }^{7,8)}$ Microstructures were observed using scanning electron microscope (SEM) with electron backscatter diffraction (EBSD). ${ }^{7)}$ Tensile test specimens with a gage length of $25 \mathrm{~mm}$ and gage width of $5 \mathrm{~mm}$ were machined from the sheets (thickness = $1.4 \mathrm{~mm}$ ). Static tensile tests were conducted with an initial strain rate of $3.3 \times 10^{-4} \mathrm{~s}^{-1}$ at various test temperatures between $77 \mathrm{~K}$ and $573 \mathrm{~K}$ by using a gear-driven-type Instron machine. ${ }^{7)}$ Here, in order to control the test temperatures, liquid nitrogen $(77 \mathrm{~K})$, environmental chamber (123-373 $\mathrm{K})$, and heating furnace $(473-573 \mathrm{~K})$ were used. ${ }^{12-14)}$ In order to investigate the effect of temperature on the DIMT behavior, test samples deformed by various true strains $(\varepsilon)$ were prepared for the $\mathrm{x}$-ray diffraction analysis. The quantitative estimation of $\gamma$ and deformation-induced martensite $\left(\alpha^{\prime}\right)$ by $\mathrm{x}$-ray diffraction was based on the principle that the total integrated intensity of all the diffraction peaks for each phase in a mixture is proportional to the volume fraction of the phase. ${ }^{12-14)}$ In this study, the increase in the volume fraction of $\alpha^{\prime}$ was considered to be the decrease in the volume fraction of $\gamma$ from the analyses of the $\gamma$ and $\alpha$ phases. ${ }^{8)}$

On the other hand, the $\mathrm{M}_{\mathrm{s}}{ }^{\sigma}$ temperature was experimentally determined by the single-specimen temperaturevariable tensile test (SS-TV-TT). ${ }^{5,15,16)}$ In the SS-TV-TT, the test specimen was given a pre-strain of approximately $0.5 \%$ and was then unloaded. The temperature was lowered by $10 \mathrm{~K}$, and the specimen was reloaded to the new $0.5 \%$ strain. This procedure was repeated at temperatures between $323 \mathrm{~K}$ and $123 \mathrm{~K}$.

\section{Results}

\subsection{Effect of Temperature on Mechanical Properties of 1-GPa-Grade TRIP Steels}

Figure 1 shows the SEM-EBSD inverse pole figure and phase maps of the needle-like $\gamma_{R}$ steel and the blocky $\gamma_{R}$ one. In the phase maps, green and red indicate $\gamma$ and $\alpha$, respectively. As reported in the previous paper, ${ }^{7,8)}$ the volume fraction of $\gamma_{R}$ before deformation $\left(V \gamma_{0}\right)$ estimated by $\mathrm{x}$-ray diffraction experiments is $24.6 \%$ for the needle-like $\gamma_{R}$ steel and $22.9 \%$ for the blocky $\gamma_{R}$ one. The matrix of the needle-like $\gamma_{R}$ steel is tempered martensite and partially bainite and that of the blocky $\gamma_{R}$ one is ferrite and bainite. ${ }^{7,8)}$ The carbon contents of $\gamma_{R}$ in the needle-like and blocky $\gamma_{R}$ steels are 1.19 mass $\%$ and 1.11 mass $\%$, respectively. Figure 2 shows the nominal stress-nominal strain curves for the needle-like $\gamma_{R}$ steel (a) and the blocky $\gamma_{R}$ one (b), obtained by tensile tests at various deformation temperatures. In Fig. 3, the nominal stress-nominal strain curves at the early stage of deformation are shown. All of nominal stress-nominal strain curves were continuous yielding type without yield drop. The nominal stress increased with a decrease in the temperature at temperatures below $373 \mathrm{~K}$, and both the TRIP steels were fractured without necking at $77 \mathrm{~K}$. On the other hand, the nominal stress increased with an increase in the deformation temperature at temperatures above 473 $\mathrm{K}^{6,9,10)}$ Figure 4 shows the $0.2 \%$ offset proof stress $(0.2 \%$ PS), tensile strength (TS), and uniform elongation (U.El) as functions of the deformation temperature. The $0.2 \%$ PS at a given temperature was larger in the needle-like $\gamma_{R}$ steel. The $0.2 \%$ PS of the blocky $\gamma_{R}$ one decreased below approximately $300 \mathrm{~K}$ and increased again below $173 \mathrm{~K}$. This seemed to be associated with the transformation strain due to DIMT before the yielding of $\gamma^{5,12,15,16)}$ On the other hand, the effect of deformation temperature on TS was almost the same for both the TRIP steels. The TS decreased with increasing temperature but increased at temperatures of above $523 \mathrm{~K}$. The U.El indicated the maximum value at $373 \mathrm{~K}$ (needle-like $\gamma_{R}$ ) and $473 \mathrm{~K}$ (blocky $\gamma_{R}$ ). Figure 5 shows U.El as a function of TS obtained by tensile tests at various temperatures in the present TRIP steels and other TRIP steels., ${ }^{3,6)}$ The dashed lines in Fig. 5 are contour lines for the products of TS and U.El. Figure 6 shows the product of TS and U.El as a function of temperature. Here, $V \gamma_{0}$ in the $0.22 \mathrm{C}$ and the $0.1 \mathrm{C}$ TRIP steels were $14.4 \%$ and $10 \%$, respectively.,6) In Fig. 5, the TS-U.El balance decreased with an increase in TS. The decrease in the TS-U.El balance with an increase in TS was larger in the present TRIP steels than in the $0.1 \mathrm{C}$ and $0.22 \mathrm{C}$ TRIP steels. ${ }^{3,6)}$ In the comparisons of the TS-U.El balance between the needle-like $\gamma_{R}$ steel and the blocky $\gamma_{R}$ one, the TS-U.El balances at TS $>1 \mathrm{GPa}$ were larger in the needle-like $\gamma_{R}$ steel. Figures 4 and 6 show that the temperature dependence of the TS-U.El balance is affected by the U.El. A better TS-U.El balance of the TRIP steels was obtained at the maximum U.El.

Figure 7 shows the work-hardening rate $(d \sigma / d \varepsilon)$ and true stress $(\sigma)$ as a function of $\varepsilon$ at various deformation temperatures for the needle-like $\gamma_{R}$ steel (a) and the blocky $\gamma_{R}$ one (b). The $d \sigma / d \varepsilon$ at a given $\varepsilon$ generally increased with a decrease in temperature. ${ }^{11,12)}$ At temperatures above 373 $\mathrm{K}$, the $d \sigma / d \varepsilon$ stopped decreasing and began to increase again. ${ }^{12-14)}$ Such $d \sigma / d \varepsilon$ behavior affects the U.El of the TRIP steels. ${ }^{7,12,13)}$ The changes in $d \sigma / d \varepsilon$ were undulated at temperatures above $373 \mathrm{~K}$. Because the $\sigma-\varepsilon$ curves are not

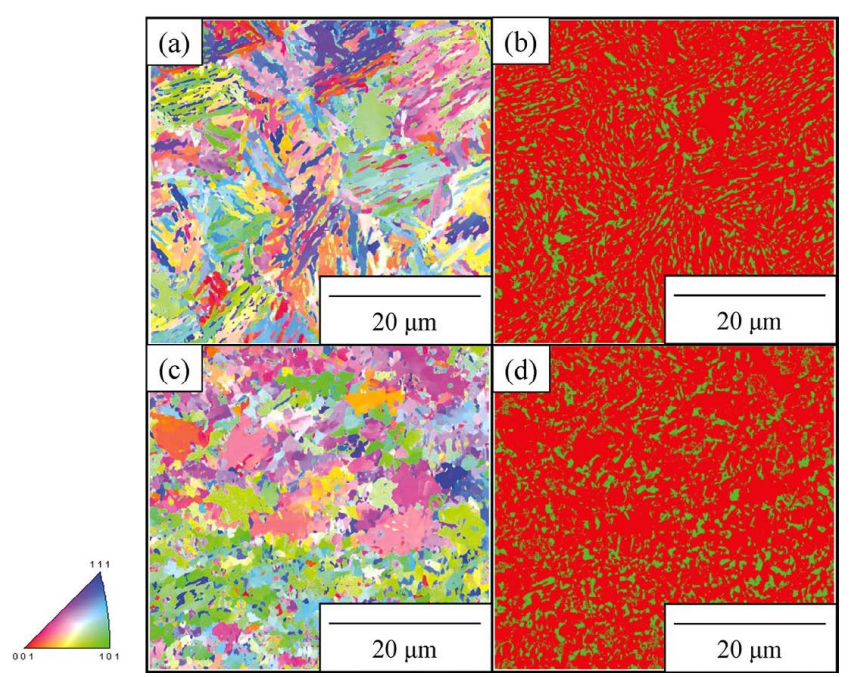

Fig. 1. Orientation color map and EBSD phase mapping image in the 1-GPa-grade TRIP steels with different $\gamma_{R}$ morphologies of needle-like ((a), (b)) and blocky ((c), (d)). (Online version in color.) 


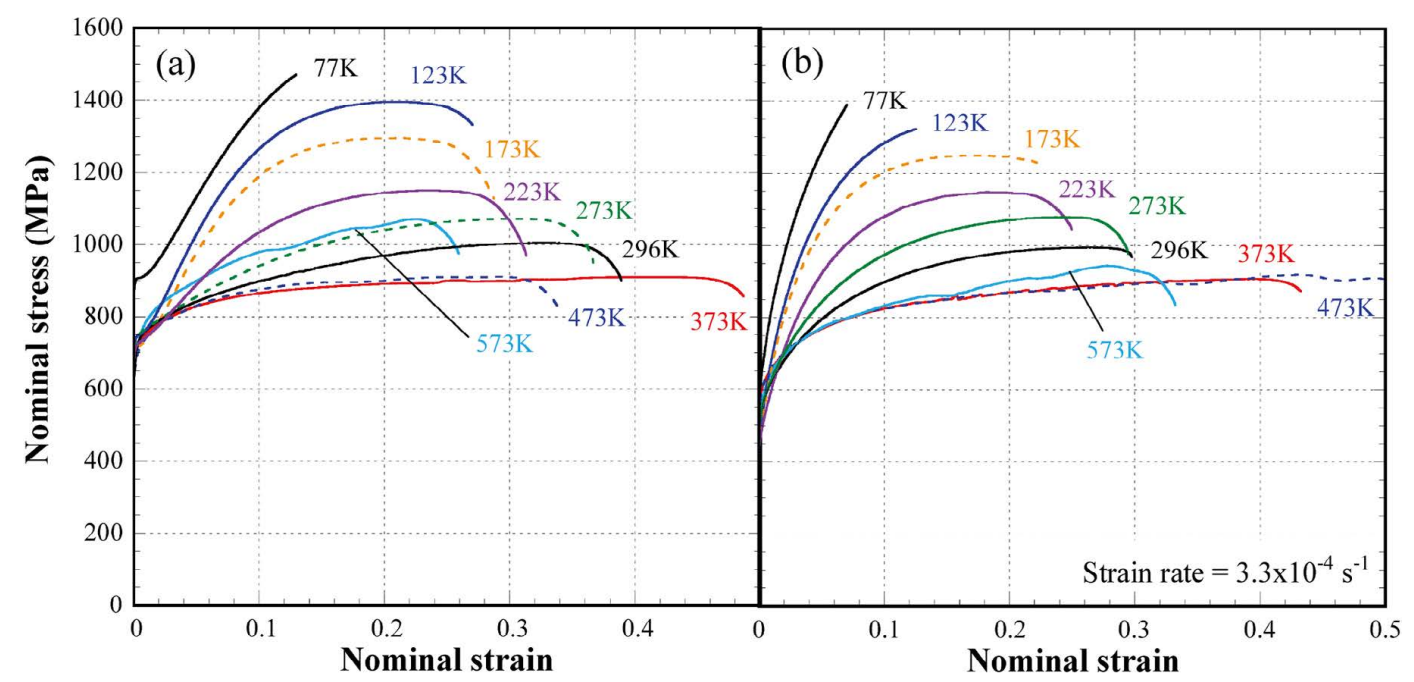

Fig. 2. Nominal stress-nominal strain curves of the 1-GPa-grade TRIP steels with different $\gamma_{R}$ morphologies of needlelike (a) and blocky (b) obtained by tensile tests at various temperatures between $77 \mathrm{~K}$ and $573 \mathrm{~K}$. (Online version in color.)

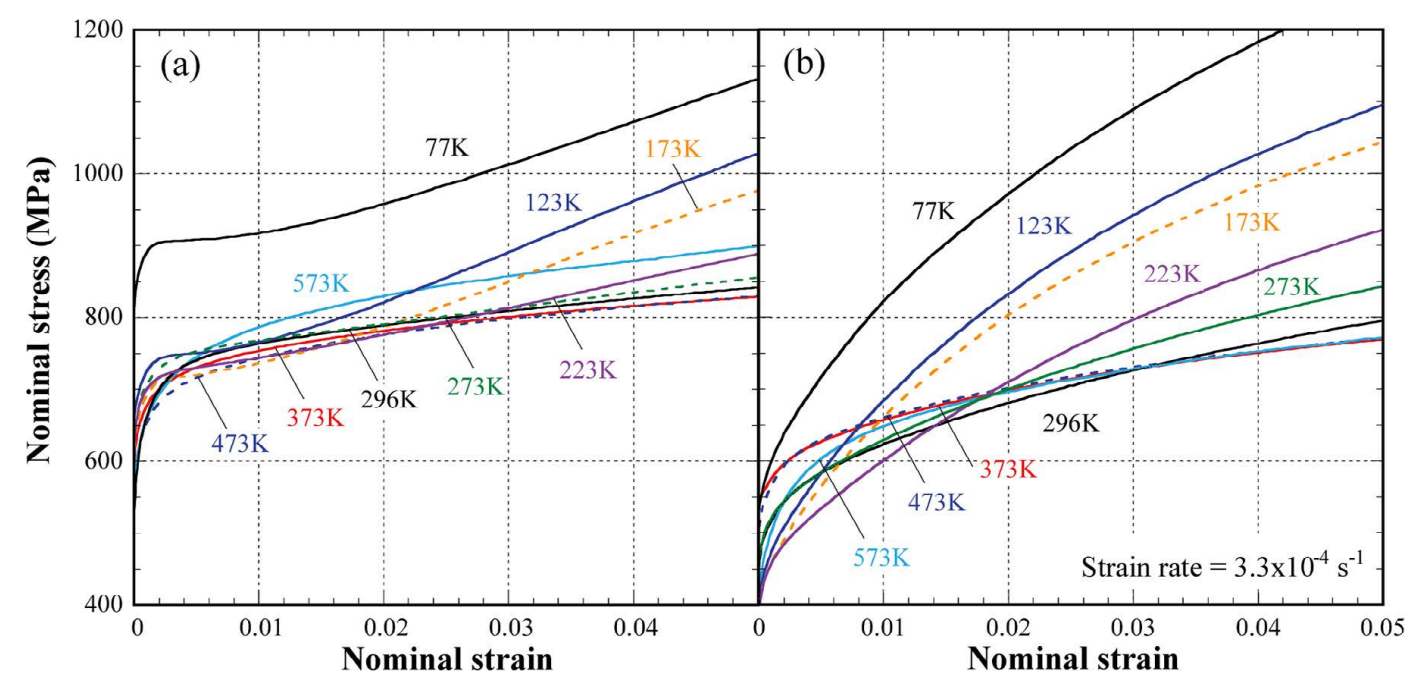

Fig. 3. Nominal stress-nominal strain curves at the early stage of deformation in Fig. 2 to show the temperature dependence of $0.2 \%$ offset proof stress of the 1-GPa-grade TRIP steels with different $\gamma_{R}$ morphologies of needle-like (a) and blocky (b). (Online version in color.)

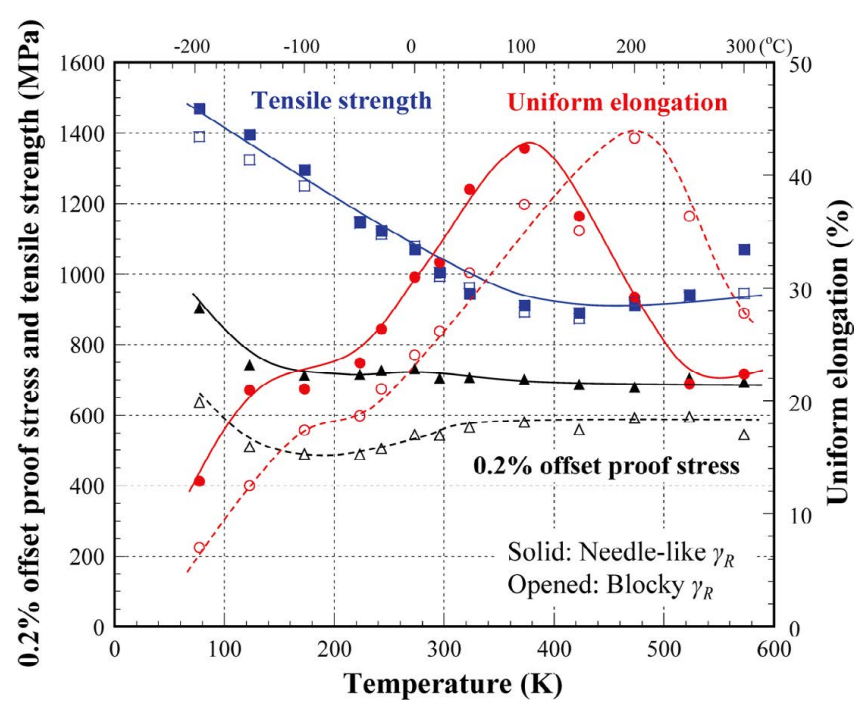

Fig. 4. $0.2 \%$ offset proof stress, tensile strength and uniform elongation as functions of temperature in the 1-GPa-grade TRIP steels with different $\gamma_{R}$ morphologies. (Online version in color.)

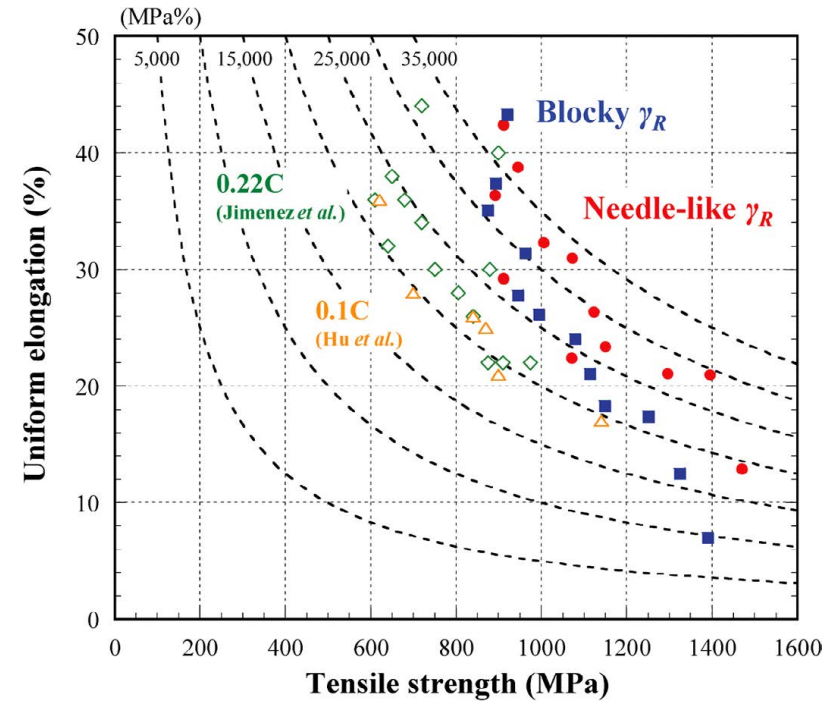

Fig. 5. Uniform elongation as a function of tensile strength in the 1-GPa-grade TRIP steels and various steels $\left(0.1 \mathrm{C}-5 \mathrm{Mn}^{3)}\right.$ and $0.22 \mathrm{C}-1.64 \mathrm{Mn}-1.51 \mathrm{Al}-0.05 \mathrm{Si}^{6)}$ steels) obtained by tensile tests at various temperatures. (Online version in color.) 


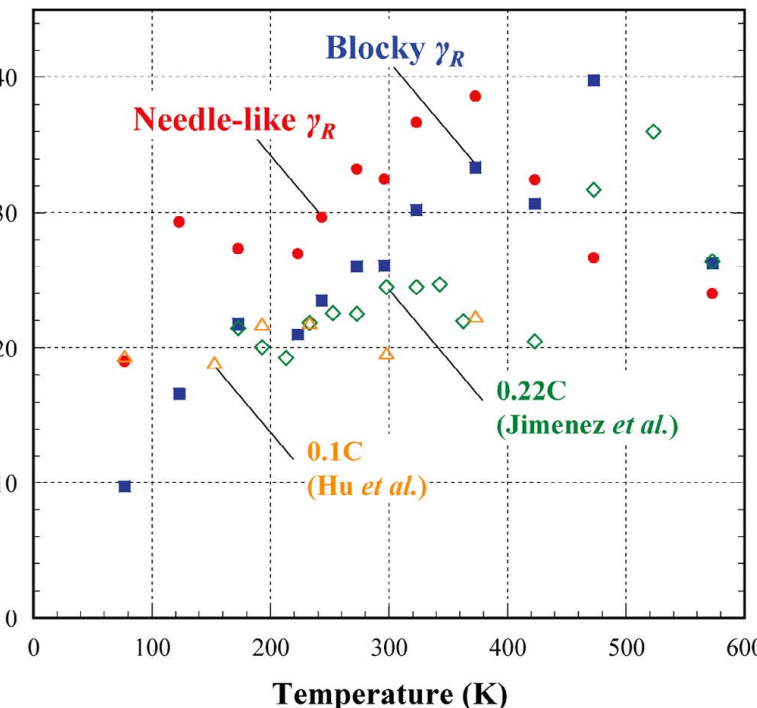

Fig. 6. Product of tensile strength and uniform elongation as a function of temperature in the 1-GPa-grade TRIP steels and various steels. ${ }^{3,6)}$ (Online version in color.) the so-called saw-toothed waves, ${ }^{9-11)}$ these $d \sigma / d \varepsilon$ behaviors are different from dynamic strain aging, judging from other studies on TRIP steels.

\subsection{Effect of Deformation Temperature on Deforma- tion-Induced Martensitic Transformation Behav- ior}

Figure 8 shows the volume fraction of $\gamma_{R}(V \gamma)$ as a function of $\varepsilon$ at various deformation temperatures for the needlelike $\gamma_{R}$ steel (a) and the blocky $\gamma_{R}$ one (b). The lines in Fig. 8 are the calculated results using the following equation formulated by Matsumura et al.: ${ }^{17)}$

$$
V_{\gamma}=\frac{V_{\gamma 0}}{1+(k / q) V_{\gamma 0} \varepsilon^{q}}
$$

where $k$ is a constant relating to mechanical stability of $\gamma_{R}$, and $q$ is the strain exponent concerning autocatalytic effect. ${ }^{17)}$ The values of $k$ and $q$ are summarized in Table 1. In the blocky $\gamma_{R}$ steel, $\gamma_{R}$ was transformed to $\alpha^{\prime}$ before the tensile tests at $77 \mathrm{~K}$ and $173 \mathrm{~K}$. The $V \gamma_{0}$ values at $77 \mathrm{~K}$ and $173 \mathrm{~K}$ were $14.8 \%$ and $17.7 \%$, respectively. In terms of the

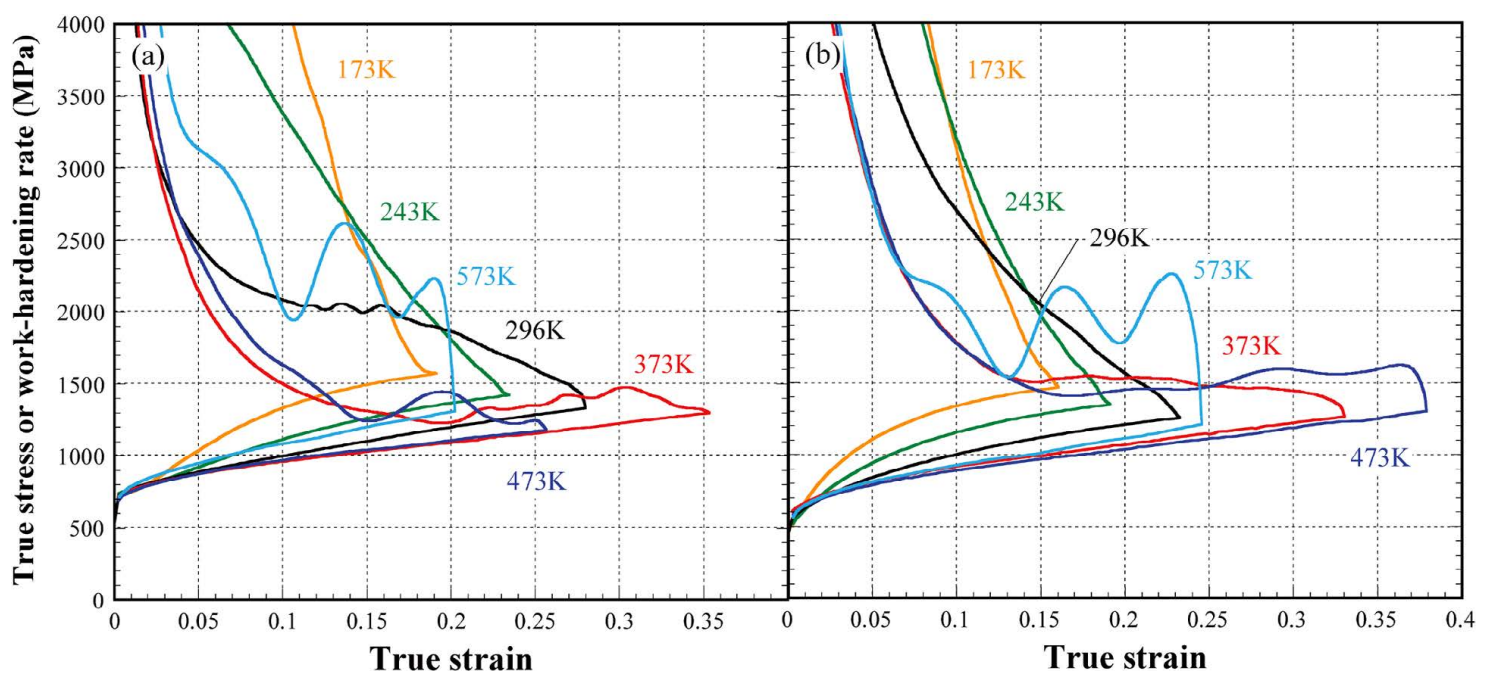

Fig. 7. True stress and work-hardening rate as functions of true strain at the temperatures between $77 \mathrm{~K}$ and $573 \mathrm{~K}$ in the needle-like $\gamma_{R}$ steel (a) and the blocky $\gamma_{R}$ one (b). (Online version in color.)

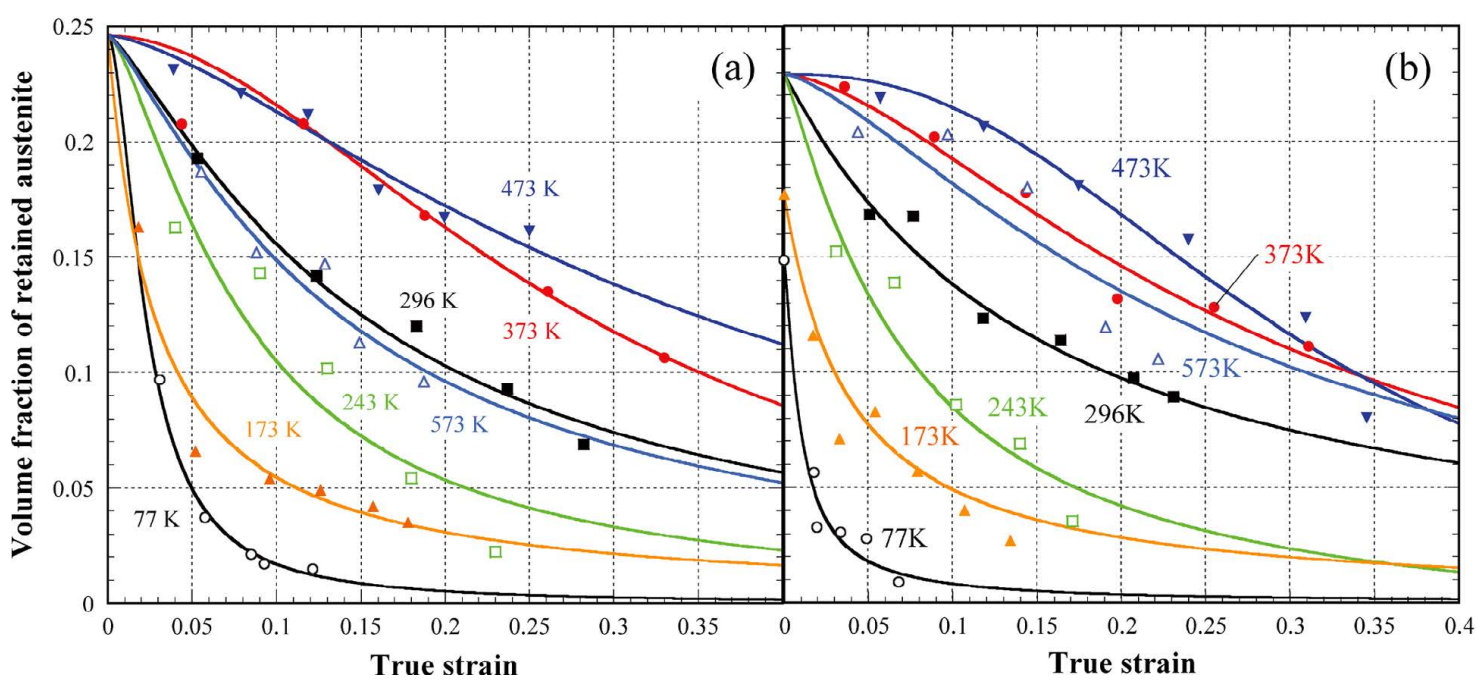

Fig. 8. Volume fraction of retained austenite as a function of true strain at the temperatures between $77 \mathrm{~K}$ and $573 \mathrm{~K}$ in the needle-like $\gamma_{R}$ steel (a) and the blocky $\gamma_{R}$ one (b). (Online version in color.) 
Table 1. Values of $k$ and $q$ in Eq. (1) in the 1-GPa-grade TRIP steels with different $\gamma_{R}$ shapes at various deformation temperatures.

\begin{tabular}{crrrr}
\hline \multirow{2}{*}{ Temperature (K) } & \multicolumn{2}{c}{ (a) Needle-like $\gamma_{R}$} & \multicolumn{2}{c}{ (b) Blocky $\gamma_{R}$} \\
\cline { 2 - 5 } & \multicolumn{1}{c}{$k$} & \multicolumn{1}{c}{$q$} & \multicolumn{1}{c}{$k$} & $q$ \\
\hline 77 & 5609.1 & 1.764 & 2361.5 & 1.226 \\
173 & 140.2 & 0.995 & 128.0 & 0.876 \\
243 & 207.0 & 1.425 & 199.1 & 1.298 \\
296 & 54.6 & 1.264 & 33.0 & 1.037 \\
373 & 78.8 & 1.871 & 60.6 & 1.764 \\
473 & 14.8 & 1.228 & 190.1 & 2.425 \\
573 & 59.3 & 1.251 & 42.2 & 1.417 \\
\hline
\end{tabular}

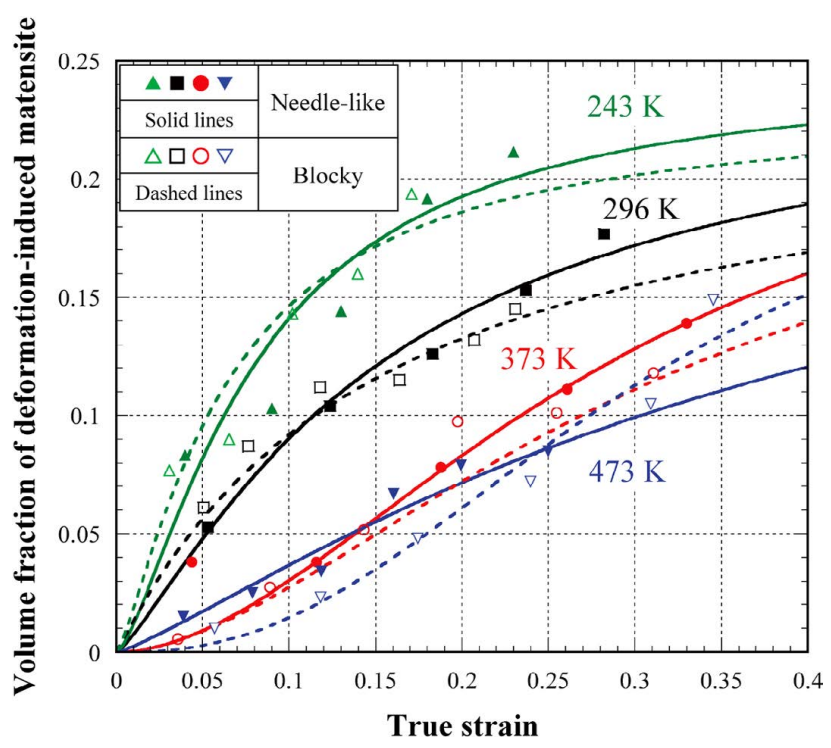

Fig. 9. Volume fraction of deformation-induced martensite as a function of true strain at $243,296,373$ and $473 \mathrm{~K}$ in the needle-like $\gamma_{R}$ steel and the blocky $\gamma_{R}$ one. (Online version in color.)

DIMT behavior at various temperatures, $V \gamma$ at a given $\varepsilon$ usually decreased with a decrease in temperature. However, $V \gamma$ at a given $\varepsilon$ decreased when the temperature increased from $473 \mathrm{~K}$ to $573 \mathrm{~K}$ in both the TRIP steels. This is different from the common temperature dependence on DIMT behavior. ${ }^{6,9,10)}$ Similar deformation-induced transformation behaviors were also reported by Sugimoto et al. ${ }^{9-11)}$ Sugimoto et al. clarified that the mechanical stability of $\gamma_{R}$ above $523 \mathrm{~K}$ in the $0.4 \mathrm{C}$ steel was mainly controlled by the deformation-induced bainitic transformation, as revealed by TEM observations. ${ }^{9)}$ During this time, TS and elongation increased with an increase in deformation temperature and indicated the maximum value near the austempering temperature. $^{9-11)}$ The increase in TS at temperatures above 523 $\mathrm{K}$, as shown in Fig. 4, also seemed to be associated with the deformation-induced bainitic transformation.

Figure 9 shows the volume fraction of $\alpha^{\prime}\left(V \alpha^{\prime}\right)$ as a function of $\varepsilon$ at $243,296,373$, and $473 \mathrm{~K}$ in order to compare the DIMT behavior between the needle-like $\gamma_{R}$ steel and the blocky $\gamma_{R}$ one. At 243, 296, and $373 \mathrm{~K}, V \alpha^{\prime}$ was larger in the needle-like $\gamma_{R}$ steel at $\varepsilon>0.15$. At $473 \mathrm{~K}, V \alpha^{\prime}$ at a given $\varepsilon$ was smaller at $\varepsilon<0.25$ but became larger at $\varepsilon>$
0.25 in the blocky $\gamma_{R}$ steel. Our previous studies at room temperature ${ }^{7,8)}$ indicated that the mechanical stability of $\gamma_{R}$ was higher in the needle-like $\gamma_{R}$ steel. Thus, the mechanical stability of $\gamma_{R}$ was higher in the needle-like $\gamma_{R}$ steel at temperatures below $373 \mathrm{~K}$. As seen in Table 1 , both of $k$ and $q$ in Eq. (1) were larger in the needle-like $\gamma_{R}$ steel at temperatures below $373 \mathrm{~K}$.

\section{Discussions}

\section{1. $\quad 0.2 \%$ Offset Proof Stress}

The $0.2 \%$ PS of the blocky $\gamma_{R}$ steel decreased below $296 \mathrm{~K}$ and increased again at $173 \mathrm{~K}$, as shown in Fig. 4. Because $\sigma$ usually increases with a decrease in temperature, the temperature dependence of $0.2 \%$ PS in the blocky $\gamma_{R}$ steel seems to be related to the $\mathrm{M}_{\mathrm{s}}{ }^{\sigma}$ point. ${ }^{5,12,15,16)}$ Figure 10 shows the nominal stress-nominal strain curves obtained by using the SS-TV-TT technique for the needle-like $\gamma_{R}$ steel (a) and the blocky $\gamma_{R}$ one (b). In the blocky $\gamma_{R}$ steel (Fig. 10 (b)), the yield point was observed at $303 \mathrm{~K}$, and the lower yield stress was almost the same between 303 and $293 \mathrm{~K}$. The yield point was also observed below $283 \mathrm{~K}$, and the lower yield stress increased a little with a decrease in the temperature. At temperatures below $183 \mathrm{~K}$, the stress-strain curves became the continuous yielding type. In the SSTV-TT technique, the $\mathrm{M}_{\mathrm{s}}{ }^{\sigma}$ temperature is designated in the case that the flow stress immediate after yielding decreases irrespective of the decreasing temperature or the yield point appears. ${ }^{5,15,16)}$ Thus, the $\mathrm{M}_{\mathrm{s}}{ }^{\sigma}$ of the blocky $\gamma_{R}$ steel can be determined as $303 \mathrm{~K}$ from Fig. 10(b), which is coincident with the temperature dependence of $0.2 \%$ PS shown in Fig. 4. The $\mathrm{M}_{\mathrm{s}}{ }^{\sigma}$ of the needle-like $\gamma_{R}$ steel was determined as 273 K from Fig. 10(a), which was lower than that of the blocky $\gamma_{R}$ one. This also means that the mechanical stability of $\gamma_{R}$ is higher in the needle-like $\gamma_{R}$ steel.

We also investigated the temperature dependence on elastic limit because the $0.2 \%$ PS contains an influence of work hardening after the plastic deformation on stress. Figure 11 shows elastic limit as a function of temperature in the needle-like $\gamma_{R}$ and blocky $\gamma_{R}$ steels. The temperature at which the elastic limit was decreased was almost coincident with the $\mathrm{M}_{\mathrm{s}}{ }^{\sigma}$ temperature of each TRIP steel. As described before, in the needle-like $\gamma_{R}$ steel, $\gamma_{R}$ was not transformed to $\alpha^{\prime}$ before the tensile tests in the present deformation temperature range. Therefore, the decrease in elastic limit of the needle-like $\gamma_{R}$ steel near the $\mathrm{M}_{\mathrm{S}}{ }^{\sigma}$ temperature is mainly associated with the DIMT before yielding of $\gamma_{R}$. On the other hand, the amount of decrease in the elastic limit near $\mathrm{M}_{\mathrm{s}}{ }^{\sigma}$ was larger in the blocky $\gamma_{R}$ steel. This seems to be correlated with the matrix microstructure. It is difficult to understand the decrease in the elastic limit from only the DIMT because the increase in $V \alpha^{\prime}$ during elastic deformation is a little. Considering that the elastic limit is affected largely by the deformation of matrix microstructure with the volume fraction of about $80 \%$, the difference of strength (or hardness) of matrix microstructure is associated with the amount of decrease in the elastic limit in Fig. 11. From Figs. 10 and 11 , we think that the inverse temperature dependency of $0.2 \%$ PS is associated with the DIMT before yielding of $\gamma_{R}$. The difference of temperature dependence on $0.2 \%$ PS between the needle-like $\gamma_{R}$ steel and the blocky $\gamma_{R}$ one 

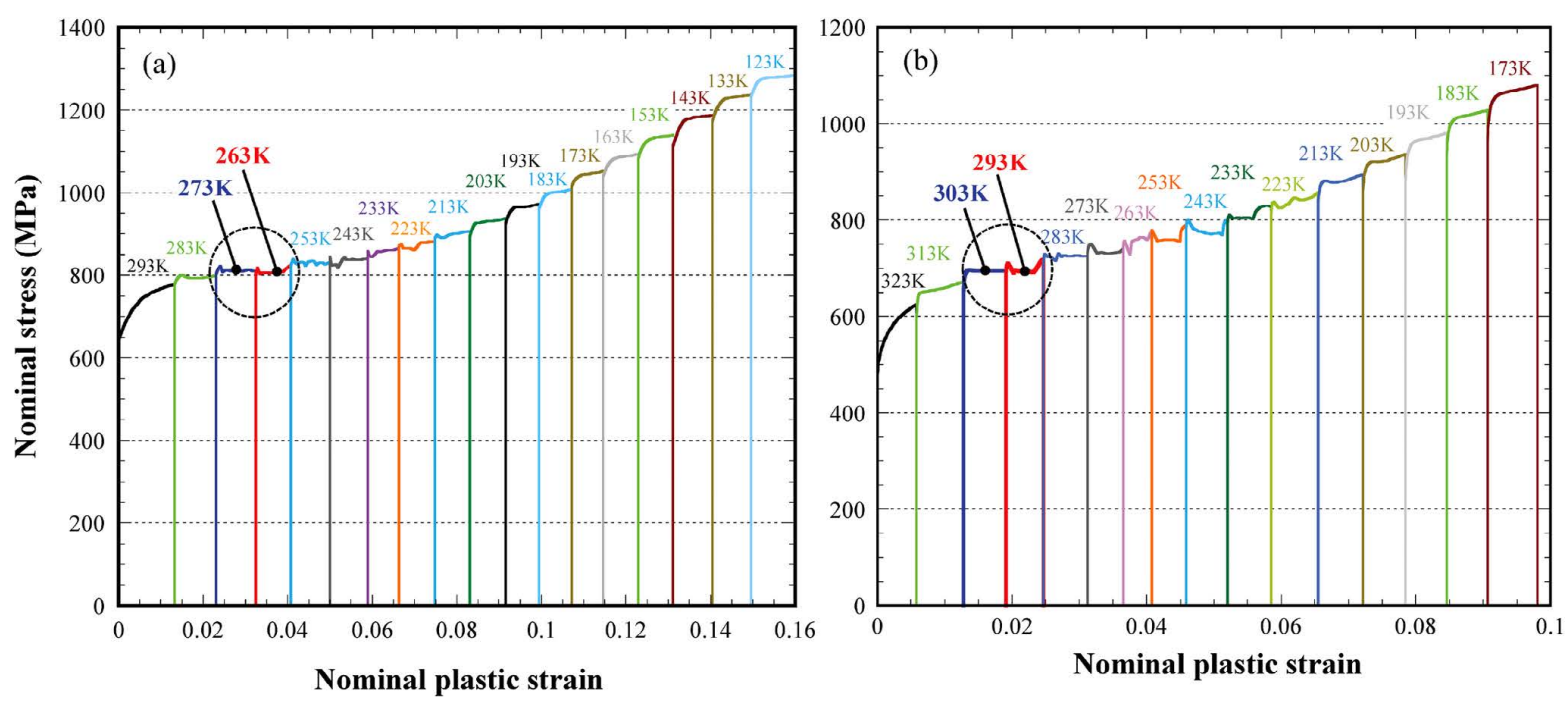

Fig. 10. Nominal stress-nominal plastic strain curves of the needle-like $\gamma_{R}$ steel (a) and the blocky $\gamma_{R}$ one (b) obtained by the SS-TV-TT technique. (Online version in color.)

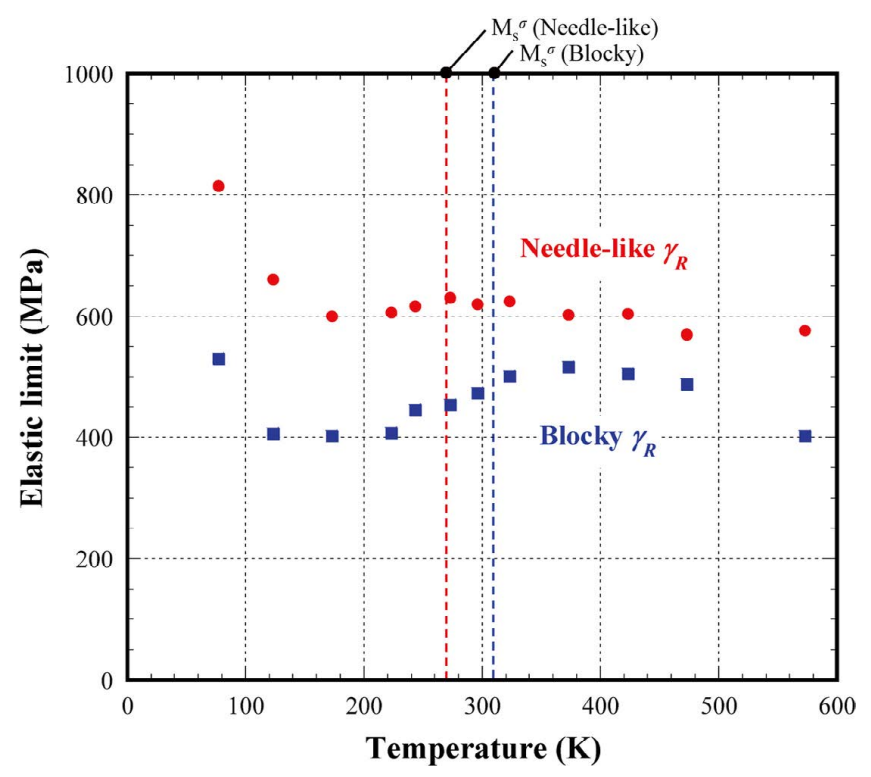

Fig. 11. Elastic limit as a function of temperature in the needlelike $\gamma_{R}$ and the blocky $\gamma_{R}$ steels. (Online version in color.)

is correlated with the mechanical stability of $\gamma_{R}$ from their $\mathrm{M}_{\mathrm{s}}{ }^{\sigma}$ temperatures and the strength of matrix microstructure.

\subsection{Tensile Strength}

Figure 12 shows the TS (a) and the true stress $(\sigma)$ at the maximum load point (b) as functions of $V \alpha^{\prime}$ at the maximum load. In Fig. 12, the experimental results of the present TRIP steels obtained by using tensile tests at various strain rates ${ }^{7)}$ and of the other TRIP steels ${ }^{6,18,19)}$ are also shown. The TS in the TRIP steels was roughly dependent on $V \alpha^{\prime}$. Harjo et $a l^{20)}$ reported that the $\sigma$ of $\alpha^{\prime}$ in the $0.2 \mathrm{C}$ TRIP steel estimated by the neutron diffraction experiments was approximately $2-2.5 \mathrm{GPa}$. In our previous study, ${ }^{8)}$ the phase strains of $\alpha^{\prime}$ in the present TRIP steels, which was associated with the $\sigma$ of $\alpha^{\prime}$, were almost the same as those in the 0.2C TRIP steel ${ }^{20)}$ and were almost independent of the $\gamma_{R}$ morphologies. These results also indicate that the $\sigma$ of $\alpha^{\prime}$ was considerably larger than those of other microstructures in TRIP steels. ${ }^{8,20,21)}$ Because $V \alpha^{\prime}$ at the maximum load at a given temperature was also almost the same, as it was independent of the $\gamma_{R}$ morphology, the TS of the present TRIP steels could be roughly determined using $V \alpha^{\prime} .^{5,6,22)}$ As shown in Fig. 12(b), the $\sigma$ at the maximum load instead of TS might be a better parameter to consider because the $\sigma$ at the maximum load is different when U.El is different even though TS is the same. Thus, the relationship between $V \alpha^{\prime}$ and the $\sigma$ at the maximum load is reasonable.

\subsection{Uniform Elongation}

As shown in Fig. 4, the temperature at the maximum U.El $\left(T_{\max }\right)$ was different between the needle-like $\gamma_{R}$ steel and the blocky $\gamma_{R}$ one. With respect to the temperature dependence on U.El in TRIP steels, the $T_{\max }$ value depended on the mechanical stability of $\gamma_{R} \cdot{ }^{6,10,12-14)}$ The higher the mechanical stability of $\gamma_{R}$ was, the lower was the $T_{\max }$ value. The carbon content of $\gamma_{R}$, which was closely related to the mechanical stability of $\gamma_{R}$, was larger in the needlelike $\gamma_{R}$ steel. $^{7,8)}$ Our previous study ${ }^{8)}$ reported that the stress partitioning between $\gamma$ and $\alpha$ also affected the mechanical stability of $\gamma_{R}$ including the DIMT behavior. In the needlelike $\gamma_{R}$ steel, the stress partitioning was small at the early stage of deformation and increased with an increase in $\varepsilon^{8)}$ In particular, the stress partitioning at the early stage of deformation was closely related to the $\sigma$ value at which the DIMT started $\left(\sigma_{D-s}\right){ }^{8}{ }^{8}$ The smaller the stress partitioning was, the larger was the $\sigma_{D-s}$ value. As shown in Fig. 9, $V \alpha^{\prime}$ at the early stage of deformation was smaller and the values at $\varepsilon>$ approximately 0.15 became larger in the needle-like $\gamma_{R}$ steel at temperatures below $373 \mathrm{~K}$. As described above, $T_{\max }$ was lower in the needle-like $\gamma_{R}$ steel with the higher mechanical stability of $\gamma_{R}$.

U.El also affected the TS-U.El balance, and a better TS-U.El balance was obtained at the maximum U.El. As shown in Fig. 5, the better TS-U.El balances of the needlelike $\gamma_{R}$ steel at the TS $>1 \mathrm{GPa}$ were associated with the temperature dependence on U.El. Considering the improvements of the mechanical properties of the 1-GPa-grade TRIP steels at room temperature, a higher mechanical stability of $\gamma_{R}$ is required. In contrast, in Fig. 6, the TS-U.El balance at $296 \mathrm{~K}$ was almost the same between the blocky $\gamma_{R}$ steel and 

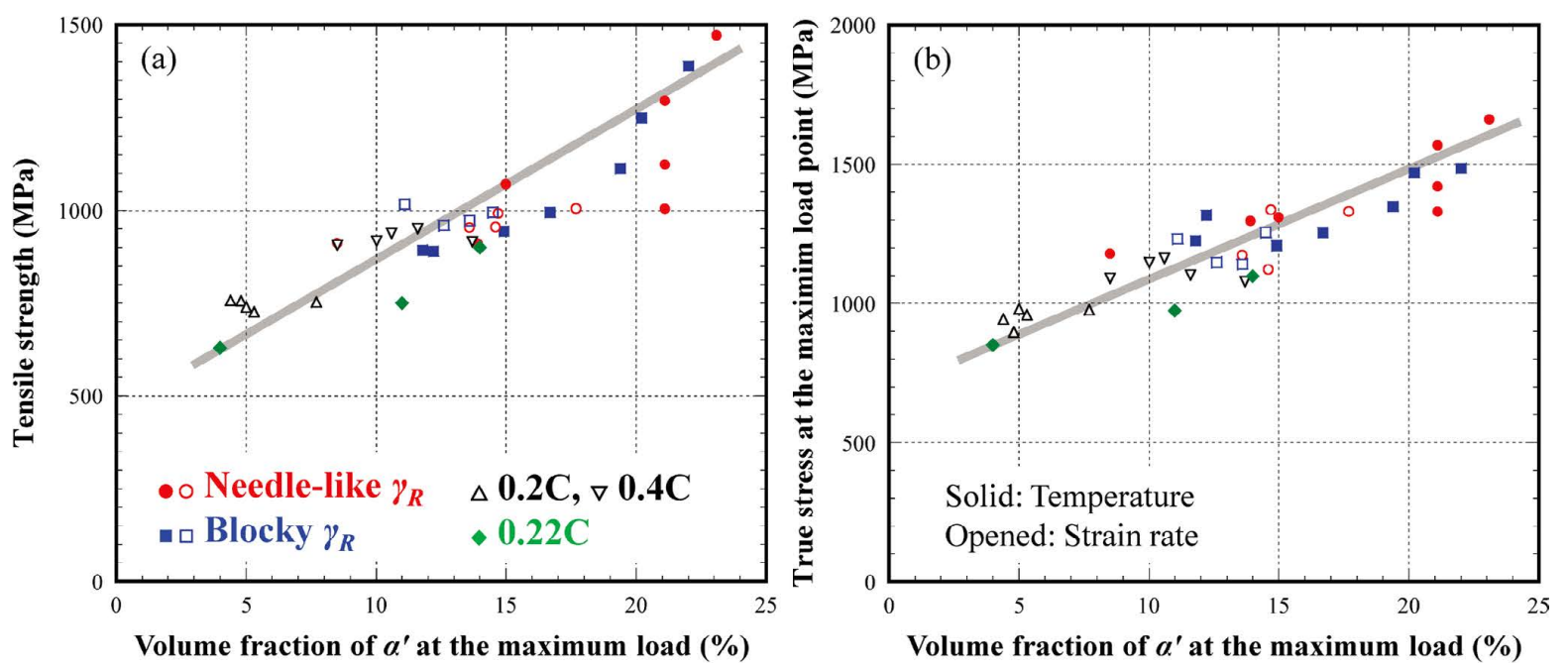

Fig. 12. Tensile strength (a) and true stress at the maximum load (b) as functions of the volume fraction of deformationinduced martensite $\left(\alpha^{\prime}\right)$ at the maximum load in the 1-GPa-grade TRIP steels and other TRIP steels. ${ }^{6,18,19)}$ (Online version in color.)

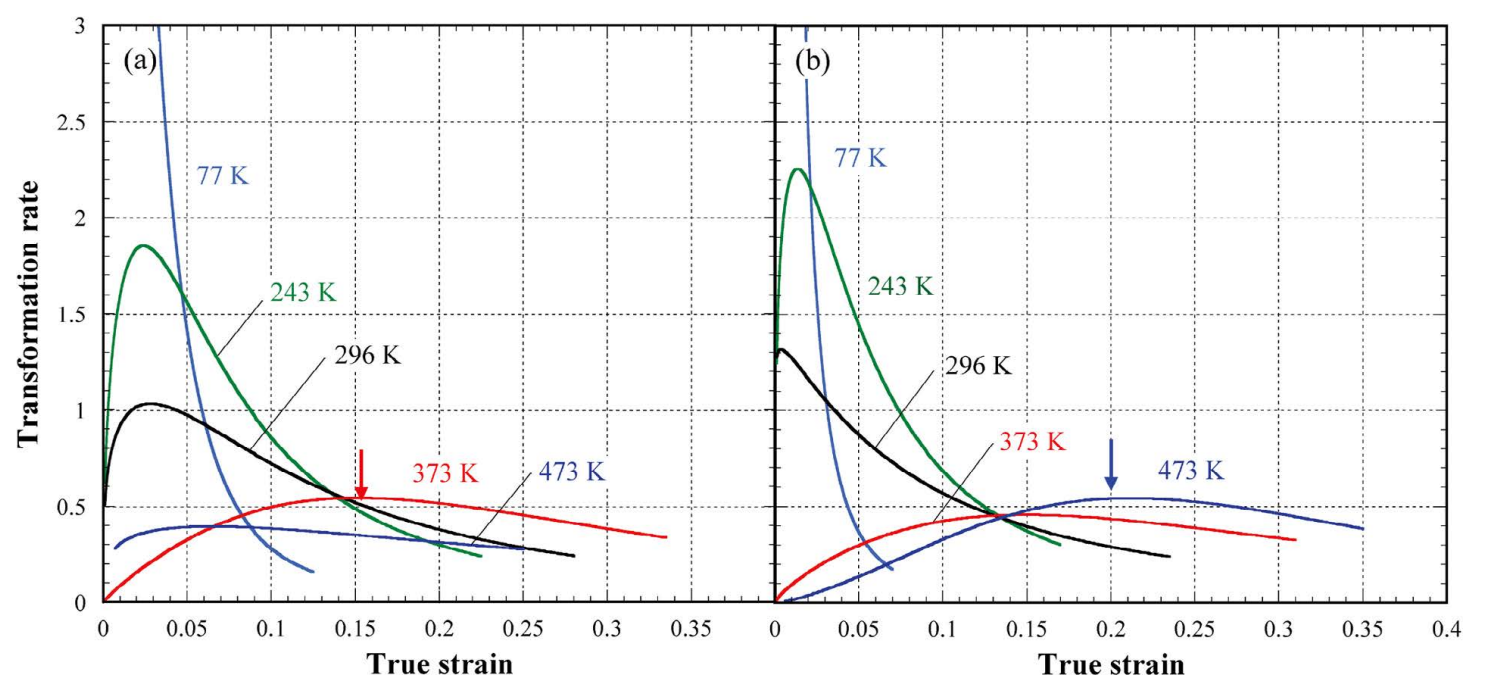

Fig. 13. Transformation rate calculated by Eq. (1) as a function of true strain at various temperatures in the needle-like $\gamma_{R}$ steel (a) and the blocky $\gamma_{R}$ one (b). (Online version in color.)

the $0.22 \mathrm{C}$ steel $\left.^{6}\right)$ despite an approximately $10 \%$ difference in $V \gamma_{0}$. This implied that a better TS-U.El balance could be obtained by the control of DIMT in spite of a smaller $V \gamma_{0}$. As a way to obtain the higher mechanical stability of $\gamma_{R}$ other than the chemical compositions, a relatively small stress partitioning between $\gamma$ and $\alpha$ is effective. ${ }^{8)}$

Next, the conditions of the DIMT behavior at $T_{\max }$ in the two TRIP steels, i.e., $373 \mathrm{~K}$ for the needle-like $\gamma_{R}$ steel and $473 \mathrm{~K}$ for the blocky $\gamma_{R}$ one, are discussed. As shown in Fig. 9, the $\gamma_{R}$ was mechanically stable in the early stage of deformation and $V \alpha^{\prime}$ increased gradually in the latter part of the deformation at $T_{\max }$. This was coincident with the qualitative condition of DIMT to obtain better U.El because of the TRIP effect, as reported in the previous studies. ${ }^{12,22,23)}$ We now summarize the quantitative conditions for the deformation-induced transformation behavior in the present TRIP steels. Here, $V \alpha^{\prime}$ and the transformation rate are focused upon as the quantitative indexes. ${ }^{12,13,23)}$ Figures 8 and 9 show that at $373 \mathrm{~K}$ for the needle-like $\gamma_{R}$ steel and at $473 \mathrm{~K}$ for the blocky $\gamma_{R}$ one, $V \alpha^{\prime}$ at $\varepsilon$ of 0.1 was less than $5 \%$ and approximately $50 \%$ of $\gamma_{R}$ was transformed to $\alpha^{\prime}$ at $\varepsilon$ of 0.3 . In the $0.22 \mathrm{C}$ TRIP steel, ${ }^{6}{ }^{6}$ as shown in Fig. 6, the maximum U.El of approximately $40 \%$ was obtained at $333 \mathrm{~K}$. From the DIMT behavior at various temperatures, ${ }^{6}$ the two conditions that $V \alpha^{\prime}$ at $\varepsilon$ of 0.1 is less than $5 \%$ and approximately $50 \%$ of $\gamma_{R}$ is transformed to $\alpha^{\prime}$ at $\varepsilon$ of 0.3 were applied in the case of the $0.22 \mathrm{C}$ steel. We also verified the two conditions for the 0.4C TRIP steel reported by Mukherjee et al. ${ }^{10)}$ As a result, the DIMT behavior at the better TS-U.El balance was almost in agreement with the two conditions. Figure 13 shows the transformation rate $\left(d V \alpha^{\prime} / d \varepsilon\right)$ estimated by using Eq. $(1)^{12,13)}$ as a function of $\varepsilon$ in the case of the needle-like $\gamma_{R}$ steel (a) and the blocky $\gamma_{R}$ one (b). The estimated $d V \alpha^{\prime} / d \varepsilon$ was shown up to the U.El at each temperature, and the arrows in Fig. 13 show the maximum $d V \alpha^{\prime} / d \varepsilon$ at $T_{\max }$ in each TRIP steel. The maximum $d V \alpha^{\prime} / d \varepsilon$ value at $\varepsilon<0.1$ was observed at most temperatures. At $T_{\max }, d V \alpha^{\prime} / d \varepsilon$ gradually increased with an increase in $\varepsilon$ and indicated the maximum value at $\varepsilon$ from 0.15 to 0.2 , as denoted by the arrows in Fig. 13. The maximum $d V \alpha^{\prime} / d \varepsilon$ value was approximately 0.5 , as this parameter was independent of the $\gamma_{R}$ morphology. From the above discussions, 
in the present 1-GPa-grade TRIP steels, the conditions of DIMT to obtain better U.El have something in common, and the following three quantitative conditions are summarized:

(i) $V \alpha^{\prime}$ at $\varepsilon$ of 0.1 is less than $5 \%$.

(ii) Approximately $50 \%$ of $\gamma_{R}$ is transformed to $\alpha^{\prime}$ at $\varepsilon$ of 0.3 .

(iii) The maximum $d V \alpha^{\prime} / d \varepsilon$ value of approximately 0.5 is indicated at larger $\varepsilon$ near uniform elongation.

\section{Summary}

In this study, the effect of deformation temperature on the mechanical properties of 1-GPa-grade TRIP steels with different $\gamma_{R}$ morphologies was clarified by tensile tests at temperatures between $77 \mathrm{~K}$ and $523 \mathrm{~K}$. The temperature dependence of the deformation-induced martensitic transformation behavior was also investigated. The main conclusions are as follows:

(1) The mechanical properties at a given temperature were greater in the needle-like $\gamma_{R}$ steel at temperatures below $373 \mathrm{~K}$. The U.El below room temperature was larger in the needle-like $\gamma_{R}$ steel, whereas the TS at each temperature was almost the same, as it was independent of the $\gamma_{R}$ morphology.

(2) The mechanical stability of $\gamma_{R}$ was higher in the needle-like $\gamma_{R}$ steel, according to the x-ray diffraction experiments. However, at temperatures more than $473 \mathrm{~K}$, the $V \alpha^{\prime}$ at a given $\varepsilon$ was larger in the needle-like $\gamma_{R}$ steel. $\gamma_{R}$ was usually mechanically stable with increasing temperature, but its volume fraction decreased at temperatures above $473 \mathrm{~K}$. It seemed to be associated with the deformation-induced bainitic transformation.

(3) From the present study, the conditions of DIMT in order to obtain better U.El in the present 1-GPa-grade TRIP steels are as follows: The maximum transformation rate of approximately 0.5 is observed at larger $\varepsilon$ and $V \alpha^{\prime}$ at $\varepsilon$ of 0.1 is less than $5 \%$. Furthermore, approximately $50 \%$ of $\gamma_{R}$ is transformed to $\alpha^{\prime}$ at $\varepsilon$ of 0.3 . These three conditions need to be studied further using TRIP steels with a wide range of $V \gamma_{0}$.

\section{Acknowledgments}

This study was obtained as a result of a commissioned project by a New Energy and Industrial Technology Development Organization (NEDO), and the support is greatly appreciated. The authors are also grateful to Mr. K. Terada and Mr. K. Takeuchi of University of Hyogo for their helps.

\section{REFERENCES}

1) W. Bleck, X. Guo and Y. Ma: Steel Res. Int., 88 (2017), 1700218. https://doi.org/10.1002/srin.201700218

2) K. Sugimoto, J. Kobayashi and T. Hojo: Tetsu-to-Hagané, 103 (2017), 1 (in Japanese).

3) J. Hu, W. Cao, C. Wang, H. Dong and J. Li: ISIJ Int., 54 (2014), 1952.

4) M. K. Hatami, T. Pardoen, G. Lacroix, P. Berke, P. J. Jacques and T. J. Massart: J. Mech. Phys. Solids, 98 (2017), 201.

5) B. C. De Cooman: Curr. Opin. Solid State Mater. Sci., 8 (2004), 285.

6) J. A. Jimenez, M. Carsi, O. A. Ruano and G. Frommeyer: Mater. Sci. Eng. A, 508 (2009), 195.

7) N. Tsuchida, S. Okura, T. Tanaka and Y. Toji: ISIJ Int., 58 (2018), 978. https://doi.org/10.2355/isijinternational.ISIJINT-2017-635

8) N. Tsuchida, T. Tanaka and Y. Toji: ISIJ Int., 60 (2020), 1349. https://doi.org/10.2355/isijinternational.ISIJINT-2019-751

9) K. Sugimoto, M. Kobayashi and S. Hashimoto: Metall. Trans. A, 23 (1992), 3085 .

10) M. Mukherjee, O. N. Mohanty, S. Hashimoto, T. Hojo and K. Sugimoto: ISIJ Int., 46 (2006), 316.

11) K. Sugimoto, M. Tsunezawa, T. Hojo and S. Ikeda: ISIJ Int., 44 (2004), 1608.

12) N. Tsuchida, Y. Morimoto, T. Tonan, Y. Shibata, K. Fukaura and R. Ueji: ISIJ Int., 51 (2011), 124.

13) N. Tsuchida, Y. Yamaguchi, Y. Morimoto, T. Tonan, Y. Takagi and R. Ueji: ISIJ Int., 53 (2013), 1881.

14) N. Tsuchida, T. Kawahata, E. Ishimaru and A. Takahashi: ISIJ Int., 54 (2014), 1971.

15) G. F. Bolling and R. H. Richman: Acta Metall., 18 (1970), 673.

16) A. N. Vasilakos, K. Papamantellos, G. N. Haidemenopoulos and W. Bleck: Steel Res., 70 (1999), 466.

17) O. Matsumura, Y. Sakuma and H. Takechi: Scr. Metall., 21 (1987), 1301.

18) N. Tsuchida and K. Osaki: Tetsu-to-Hagané, 99 (2013), 524 (in Japanese).

19) N. Tsuchida, T. Araki, Y. Yamaguchi and K. Fukaura: Tetsu-toHagané, 98 (2012), 558 (in Japanese).

20) S. Harjo, N. Tsuchida, J. Abe and W. Gong: Sci. Rep., 7 (2017), Article No. 15149. https://doi.org/10.1038/s41598-017-15252-5

21) Y. Tomota, H. Tokuda, Y. Adachi, M. Wakita, N. Minakawa, A. Moriai and Y. Morii: Acta Mater., 52 (2004), 5737.

22) P. J. Jacques, E. Girault, P. Harlet and F. Delannay: ISIJ Int., 41 (2001), 1061.

23) I. Tamura: Tetsu-to-Hagané, 56 (1970), 429 (in Japanese). 